\title{
SAÚDE VOCAL E CONDIÇÕES DE TRABALHO NA PERCEPÇÃO DOS DOCENTES DE EDUCAÇÃO BÁSICA
}

\author{
Gustavo Bicalho Gonçalves"
}

Dalila Andrade Oliveira**

\begin{abstract}
RESUMO
$\mathrm{O}$ artigo discute a saúde vocal e o bem-estar dos docentes, relacionando-os com as percepções dos docentes sobre suas condições de trabalho. A partir de reflexões gerais sobre os riscos à saúde dos docentes, identificados e problematizados em pesquisas focadas na análise das condições de trabalho escolar, procurou-se desenvolver algumas análises de dados quantitativos resultantes da pesquisa Trabalho Docente na Educação Básica no Brasil (TDEBB). Foram criados três grupos de docentes segundo sua vivência de problemas de voz: o grupo E, sem problemas de voz; o grupo R, de risco para os problemas de voz; e o grupo $\mathrm{D}$, diagnosticado com problemas de voz. A conformação desses três grupos foi analisada em quatro níveis: características dos docentes, contexto profissional, contexto ambiental e contexto global. Foram ainda desenvolvidas análises qualitativas apoiadas nos relatos dos docentes em grupos focais. Fatores de risco e de proteção à saúde, relacionados às condições de trabalho, são apontados a fim de possibilitar a promoção de um ambiente de trabalho mais saudável, o que pode vir a contribuir para a melhoria na qualidade da educação e valorização da profissão docente.
\end{abstract}

Palavras-chave: Trabalho docente. Saúde vocal. Saúde e trabalho. Condições de trabalho.

\section{ABSTRACT \\ VOCAL HEALTH AND WORKING CONDITIONS IN THE PERCEPTION OF BASIC EDUCATION TEACHERS \\ The article discusses the vocal health and the well-being of teachers, relating them with teachers' perceptions about their working conditions. From general reflections on teachers' health risks identified and problematized in researches that focused on school working conditions analysis, we developed quantitative data analysis based on the Teaching Work in Basic Education in Brazil (TDEBB) research. It was created three groups of teachers according to their voice problems experience: the E group, without voice problems; the $\mathrm{R}$ group, of risk for voice problems and the $\mathrm{D}$ group, diagnosed}

\footnotetext{
* Doutor em Políticas Públicas e Formação Humana pelo Programa de Pós-Graduação em Políticas Públicas e Formação Humana da Universidade do Estado do Rio de Janeiro. Integrante do Grupo de estudos sobre gestão escolar e trabalho docente, da Universidade Federal de Minas Gerais (UFMG). Professor Adjunto do Instituto de Humanidades, Artes e Ciências da Universidade Federal do Sul da Bahia (UFSB). Fonoaudiólogo e Psicólogo. gustavobrunobg@gmail.com

** Doutora em Educação pela Universidade de São Paulo (USP). Professora Titular da Faculdade de Educação e do Programa de Pós-Graduação em Educação da Universidade Federal de Minas Gerais (UFMG). Pesquisadora PQ-1Ado CNPq. dalilaufmg@ yahoo.com.br
} 
with voice problems. These three groups were analyzed at four levels: characteristics of teachers, professional context, environmental context and global context. Other qualitative analyses were supported by the reports of teachers in focus groups. Risk and health protection factors related to working conditions are appointed in order to promote a healthier work environment, which may ultimately contribute to improving the quality of education and teaching profession valorization.

Keywords: Teaching. Vocal health. Health and work. Working conditions.

\section{RESUMEN}

\section{SALUD VOCAL Y CONDICIONES DE TRABAJO EN LA PERCEPCIÓN DE LOS DOCENTES DE EDUCACIÓN BÁSICA}

El artículo discute salud vocal y bienestar de los docentes, relacionándolos con las percepciones de éstos sobre sus condiciones de trabajo. A partir de reflexiones generales sobre los riesgos de la salud de los docentes identificados y problematizados en investigaciones que enfocan el análisis de las condiciones de trabajo escolar, se buscó desarrollar algunos análisis de datos cuantitativos resultantes de la investigación Trabajo Docente en Educação Básica en el Brasil (TDEBB). Fueron creados tres grupos de docentes según su vivencia de problemas de voz: el grupo E, sin problemas de voz; el grupo R, de riesgo para los problemas de voz; y el grupo D, diagnosticado con problemas de voz. A conformación de estos tres grupos fue analizada en cuatro niveles: características de los docentes, contexto profesional, contexto ambiental y contexto global. Además, se realizaron análisis cualitativos apoyados en los relatos de los docentes en grupos focales. Factores de riesgo y de protección a la salud, relacionados con las condiciones de trabajo son señalados con el objeto de posibilitar la promoción de un ambiente de trabajo más saludable, lo que puede contribuir para mejorías en la calidad de la educación y para la valorización de la profesión docente.

Palabras clave: Trabajo docente. Salud vocal. Salud y trabajo. Condiciones de trabajo.

\section{Saúde vocal e condições de trabalho na percepção dos docentes de educação básica}

A saúde dos docentes tem sido cada vez mais objeto de interesse das políticas públicas de educação pelo alto número de ausências ao trabalho e afastamentos médicos. No momento em que as preocupações se voltam para as dificuldades de reter e atrair bons professores para assumir os sistemas públicos de educação (ORGANIZATION FOR ECONOMIC CO-OPERATION AND DEVELOPMENT, 2005), as condições de trabalho e sua possível relação com a saúde e o bem-estar dos docentes passa a merecer maior atenção.

As preocupações com o que vem sendo conhecido como a falta de atratividade na carreira docente envolve um conjunto de fatores em que as condições de trabalho oferecidas a esses profissionais se destacam, especialmente se consideramos as múltiplas expectativas que são depositadas na educação e, consequentemente, nos professores. Essas amplas expectativas têm sido causa de desconforto e sofrimento dos docentes que, por não terem asseguradas as condições necessárias para o bom desenvolvimento de suas atividades, muitas vezes se frustram, sentem-se desestimulados e acabam por desistir da profissão. Diante desse quadro nos propusemos a discutir a relação entre as condições de trabalho oferecidas nas unidades de educação básica pública no país e a saúde dos seus profissionais docentes, a partir de dados de pesquisa realizada no contexto escolar brasileiro.

Neste texto, nosso propósito é discutir alguns problemas que, na percepção dos docentes, têm 
afetado o seu bem-estar, relacionando-os com as condições de trabalho que são oferecidas pelas unidades educativas em que atuam. Tratam-se de reflexões gerais sobre os riscos à saúde no trabalho docente, identificados e problematizados em pesquisas focadas na análise das condições de trabalho escolar. As discussões aqui empreendidas são fundamentadas especificamente em dados da pesquisa Trabalho Docente na Educação Básica no Brasil (TDEBB) (OLIVEIRA; VIEIRA, 2010), desenvolvida e coordenada pelo Grupo de Pesquisa sobre Política Educacional e Trabalho Docente da Universidade Federal de Minas Gerais (Gestrado/ UFMG). Essa pesquisa gerou dois bancos de dados: o primeiro deles sendo resultado de entrevistas com docentes em atividade nas unidades educativas (creches, escolas de ensino fundamental e médio), realizadas nos anos de 2009 e 2010, com 8.795 entrevistas em sete estados brasileiros: Espírito Santo, Goiás, Minas Gerais, Pará, Paraná, Rio Grande do Norte e Santa Catarina; e o segundo foi produzido a partir da pesquisa realizada no estado de Pernambuco no ano de 2013, tendo sido entrevistados 981 sujeitos docentes.

Os sujeitos docentes foram definidos na pesquisa TDEBB como "os profissionais que desenvolvem algum tipo de atividade de ensino ou docência, sendo compreendidos pelos professores e por outros profissionais que exercem atividade de docência" (OLIVEIRA; VIEIRA, 2010, p. 15), o que inclui os educadores que atuam em creches e pré-escolares nas mais diversas nomenclaturas que assumem pelas redes públicas municipais $\mathrm{e}$ estaduais do país, os auxiliares em educação especial, os oficineiros e estagiários que trabalham nas escolas de tempo integral, entre outros profissionais que estão diretamente relacionados ao processo educativo nas unidades educacionais.

Além dos bancos de dados produzidos com os resultados das entrevistas, foram realizados, durante o ano de 2013, 42 grupos focais, envolvendo 384 docentes, em cinco capitais dos estados amostrados na pesquisa (Belém, Belo Horizonte, Curitiba, Goiânia e Recife), localizadas nas diferentes regiões geográficas do país. Após a realização desses grupos focais com docentes que foram mobilizados nas unidades educacionais sorteadas, dentre aquelas pertencentes à amostra dos dois surveys (2010 e 2013), foram feitas as transcrições das gravações e o tratamento das informações por meio de um software (N'Vivo10) de análise qualitativa.

Tanto nos questionários utilizados nas entrevistas realizadas na unidades educacionais quanto nos roteiros dos grupos focais, buscou-se obter dados relacionados às condições de trabalho e à saúde dos docentes. No questionário constavam ainda blocos de questões relacionadas ao perfil e formação do entrevistado, sua forma de inserção na profissão, seu conhecimento sobre a carreira e as políticas educacionais vigentes, sua percepção com relação à gestão e organização da unidade educativa, o sindicato e organização política dos docentes, entre outras informações relevantes para a compreensão de sua situação no contexto escolar. Dessa forma, a pesquisa permite a realização de uma abordagem ampla dos problemas vividos pelos docentes, com um enfoque centrado no contexto escolar brasileiro.

Para as análises pretendidas no escopo deste texto, consideramos inicialmente apenas os dados quantitativos, obtidos na pesquisa nacional realizada nos sete estados brasileiros, no ano de 2010, por serem dados mais representativos em nível nacional, e os grupos focais realizados nas cinco capitais brasileiras amostradas na segunda fase da pesquisa TDEBB - Fase II: Belém, Belo Horizonte, Curitiba, Goiânia e Recife.

\section{As condições de trabalho e a saúde docente: discutindo os dados da pesquisa}

Nas análises empreendidas neste artigo, tomaremos como elemento central as informações relativas ao afastamento do trabalho por problemas de saúde, declaradas pelos entrevistados no momento da pesquisa em campo. A partir desse corte é que tentaremos estabelecer os nexos de nossa interpretação dos dados. Sendo assim, não estaremos lidando com sintomas ou queixas dos entrevistados, ainda que esses sejam elementos importantes para a compreensão das relações entre saúde e trabalho no contexto escolar.

De acordo com Murta (2001),

O sintoma deve ser interpretado como um substituto, disfarçado e deformado, de um desejo, de uma 
ideia reprimida, de algo que, inconscientemente, os professores negam em si mesmos; resultado de uma elaboração psíquica, ele é a expressão de um conflito. Enquanto tal, o sofrimento psíquico de professores deve ser tomado como expressão de um conflito por eles vivido no âmbito dessa profissão, situação que, por sua vez, denuncia um mal-estar mais profundo e abrangente.

A voz e os sintomas relacionados ao seu uso intensivo no trabalho docente são um caso de estudo a parte, pois indicam a centralidade que ocupa em todo processo pedagógico. Considerando que a voz é um dos principais meios de comunicação entre professores e alunos, ferramenta fundamental para o desempenho de suas atividades, e que a falta dela pode acarretar sérios problemas nas formas tradicionais de ensinar, como podemos constatar nas história da ideias pedagógicas, ${ }^{1}$ é imperioso compreender os usos que os docentes fazem de sua voz e os desgastes associados a ele. Sabemos que o uso da voz na atividade docente está inserido em um contexto muitas vezes conflituoso, por isso é importante observar a forma como docentes no exercício do seu trabalho se relacionam com seus alunos, seus pares, a direção escolar e com outros aspectos que podem interferir no seu bem-estar e no uso de sua voz. Conforme sugere Behlau (2001), aspectos psicossociais não só interferem na produção da voz como podem levar a casos de adoecimento. Os dados da pesquisa apontam para uma clara diferença na avaliação que os docentes fazem de seu trabalho, na qual a vivência com os alunos é aspecto fundamental.

A partir dos dados quantitativos (OLIVEIRA; VIEIRA, 2010) foram criados três grupos de docentes segundo sua vivência de problemas de voz: o grupo E, sem problemas de voz, o grupo R, de risco para os problemas de voz, e o grupo D, diagnosticado com problemas de voz.

$\mathrm{O}$ grupo $\mathrm{R}$ foi definido em razão de haver respondido positivamente ("de vez em quando" ou "diariamente") a uma das seguintes questões: Nas duas últimas semanas você tem sentido cansaço para falar? Nas duas últimas semanas você tem percebido piora na qualidade da sua voz? O grupo E foi composto de sujeitos que responderam negati-

1 Referimo-nos à experiência de Celestin Freinet e suas contribuições ao movimento da Escola Nova. vamente, "nunca", às questões acima, e não tiraram licença por problemas de voz. O grupo D foi criado para controlar variáveis ligadas ao autodiagnóstico e está composto de docentes que se afastaram do trabalho por licença médica devido a problemas de voz durante algum período nos últimos 24 meses (anteriores à realização da entrevista).

O perfil desses três grupos foi analisado em quatro níveis. $\mathrm{O}$ primeiro deles aprofunda-se no estabelecimento das características dos docentes e analisa seu perfil sociodemográfico (idade, sexo) e experiências relacionadas à sua vivência profissional. Posteriormente, foram comparados dados relativos ao contexto profissional, em que se analisa dados relativos à sua ocupação: cargo ocupado, natureza do vínculo empregatício, etapa da educação básica em que atua, carga horária de trabalho, tempo de trabalho em educação e presença de medidas de proteção para a voz. Em um terceiro nível é analisado o contexto ambiental do trabalho docente, considerando-se as condições do espaço físico das escolas, de um modo geral. Por último, o contexto global volta-se para a análise de condições que levariam a uma intensificação do trabalho docente como presença ou não de apoio na realização de suas atividades, número de alunos em média por turma e presença de trabalho coletivo.

Esses quatro níveis de análise (Figura 1) permitem identificar correlações entre aspectos da vida e do trabalho dos docentes e a prevalência de sintomas e diagnósticos. A elaboração desses níveis de análise atenta para a literatura específica da área que tem apontado para fatores de risco ambientais como presença de ruído elevado na sala de aula, ventilação precária e trabalhar em outra atividade com uso intensivo da voz (MEDEIROS; BARRETO; ASSUNÇÃO, 2008); outros fatores de risco relacionados à carga de trabalho, intensificação do trabalho e precarização das condições de trabalho, conforme identificado por Araújo e colaboradores (2008); variáveis subjetivas, como a percepção da desvalorização profissional, vivência da relação com os alunos e perspectivas de trabalho no futuro, conforme sugestionado por Assunção e Oliveira (2009), que afirmam que a ampliação das demandas profissionais sem o suporte social e a precarização das condições de trabalho, juntamente com a desvalorização profissional, refletem na saúde da voz 
do professor. As medidas de proteção para a voz empregadas pelos docentes também se conforma- ram em uma variável que correlacionamos aos três grupos criados.

Figura 1 - Níveis de análise das condições favoráveis e obstáculos à saúde

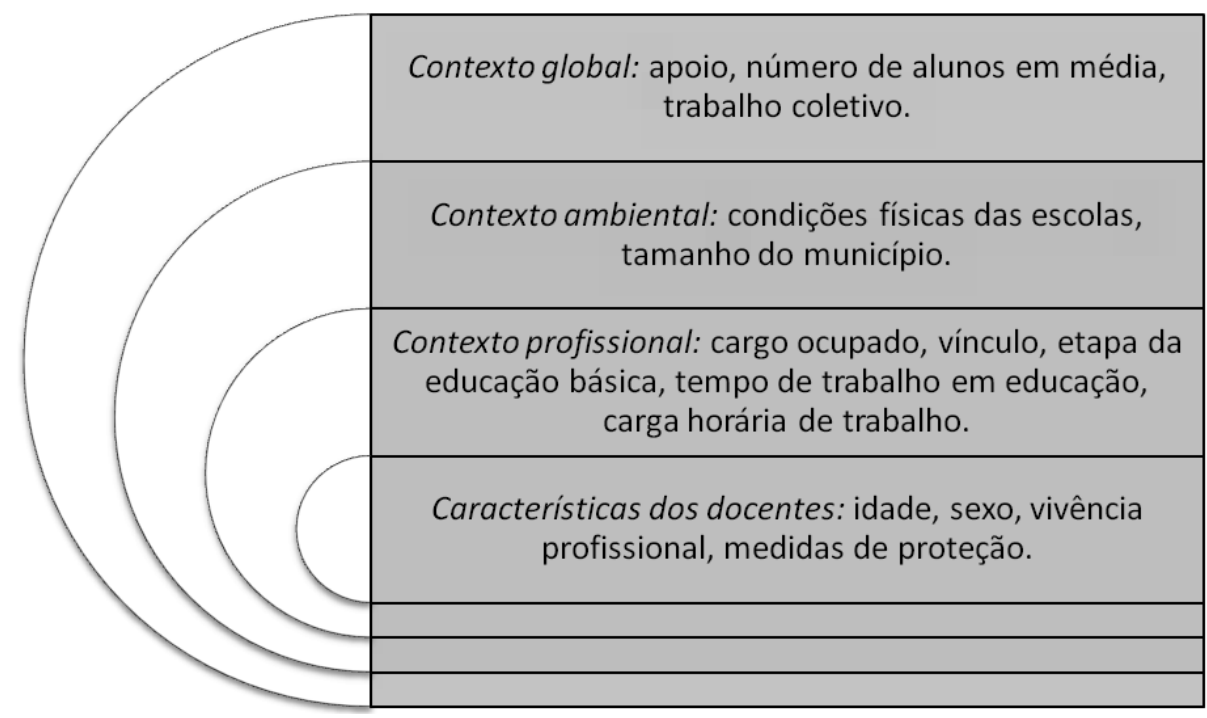

Fonte: Elaborada pelos autores deste artigo.

\section{Características dos docentes}

São reagrupadas aqui as variáveis sociodemográficas de sexo e idade dos respondentes da amostra, bem como variáveis subjetivas, relacionadas à vivência profissional dos docentes. As medidas de proteção à saúde e de prevenção aos problemas de voz adotados pelos docentes, tendo em vista a promoção da sua saúde em geral, também são analisadas. $\mathrm{O}$ interesse aqui é identificar o fator individual na composição dos riscos para a saúde vocal na unidade educativa. É claro que ao analisarmos a dimensão individual não podemos ignorar que ela se situa sempre em relação ao contexto, contudo, aqui a ênfase será nas características mais específicas de cada docente.

\section{Características sociodemográficas}

O sexo e a idade correlacionam-se com muitas das variáveis que serão analisadas aqui. Como é sabido, a profissão docente na educação básica é majoritariamente feminina, sobretudo nas etapas iniciais, educação infantil e primeiro segmento do ensino fundamental, o que em certa medida está associado a determinados contextos profissionais e ambientais, que determinarão as condições de trabalho dos docentes. A idade, por sua vez, se associa ao tempo de trabalho na educação e ao vínculo de emprego, ambos fatores determinantes do contexto profissional a que os docentes estão submetidos. Nas análises que prosseguem neste artigo, trataremos de evidenciar algumas dessas relações.

A partir dos dados da pesquisa observou-se que as mulheres apresentam maior tendência a relatar sintomas relacionados a problemas de voz. Enquanto $52 \%$ delas $(\mathrm{n}=7187)$ se enquadram no grupo D, os homens são apenas $46 \%$. No grupo D constatamos a presença de 209 mulheres $(2,9 \%)$ e 30 homens (1,9\%). Já o grupo E está representado por $45 \%$ das mulheres e $52 \%$ dos homens.

Além do sexo, outro fator de risco que deve ser considerado para problemas de voz é a idade. Uma idade mais avançada e maior tempo de docência podem estar correlacionados com uma maior probabilidade de tirar licença por problemas de voz. O grupo D é levemente sobrerrepresentado na faixa etária de 46 a 68 anos de idade (39,2\% contra $33,8 \%$ do grupo E). Estes dados são confirmados na 
literatura científica (BEHLAU, 2001), que aponta para uma maior prevalência de problemas de voz entre mulheres e entre pessoas com mais idade.

\section{Vivência profissional e a vivência da relação com os alunos}

A vivência profissional e a vivência da relação com os alunos são importantes na medida em que são definidores de atitudes e crenças a respeito dos papéis que os docentes devem assumir no seu trabalho. A vivência profissional refere-se a aspectos subjetivos ligados aos sentimentos dos docentes com o seu trabalho. Observa-se que os grupos de risco ou diagnosticados fazem uma avaliação mais negativa de sua vivência profissional que o grupo eufônico.

Ao reagir à afirmação "eu me sinto frustrado com o meu trabalho", o grupo E relatou sentir-se assim sempre ou frequentemente em $19 \%$ dos casos, o grupo R em $35 \%$ e o grupo D em $31 \%$. Concordaram com a afirmação "eu sinto que tenho muito a contribuir na educação" $96 \%$ dos respondentes do grupo E, 95\% do grupo R e 98\% do grupo D, não se observando portanto uma diferença significativa entre os grupos. Concordaram com a afirmação "eu penso em parar de trabalhar na educação" 19\% do grupo E, $29 \%$ do grupo R e $33 \%$ do grupo D, o que pode estar revelando uma forte associação entre distúrbios vocais e a vontade de abandonar a profissão. Concordaram com a afirmação "trabalhar na educação me proporciona grandes satisfações" $83 \%$ dos respondentes do grupo E, $73 \%$ do grupo R e $77 \%$ do grupo D. Concordaram com a afirmação "eu escolheria ainda trabalhar em educação, se eu tivesse que recomeçar minha vida profissional" $70 \%$ dos respondentes do grupo E, $60 \%$ do grupo $\mathrm{R}$ e $58 \%$ do grupo D. Concordaram com a afirmação "eu sinto que a educação me permite utilizar ao máximo minhas capacidades" $78 \%$ dos respondentes do grupo E e 70\% dos grupos R e D. Em relação à afirmação "eu penso que, em outra profissão, eu utilizaria melhor minhas habilidades intelectuais", o grupo E concordou em $23 \%$ dos casos e os grupos R e D em 33\% dos casos. À afirmação "eu sinto que meu trabalho poderia ser mais eficiente, se fosse planejado e executado em condições mais favoráveis", o grupo E concordou em $85 \%$ dos casos, o grupo R em 90\% e o grupo D em $87 \%$, sugerindo que o reconhecimento de condições de trabalho desfavoráveis está associado ao perfil de risco para distúrbios de voz.

Os dados indicam, portanto, que de modo geral os docentes com perfil de risco para distúrbios vocais percebem sua profissão como mais desvalorizada socialmente e possuem uma pior vivência profissional que seus pares eufônicos. Eles tendem a perceber sua profissão mais como fonte de sofrimento e frustração e menos como fonte de prazer e realização pessoal e profissional.

Considerando que a voz é um dos principais meios de comunicação entre professores e alunos, como já destacamos na introdução desta discussão, o desafio que se coloca é compreender como os docentes têm usado sua voz e quais são os desgastes associados a esse uso. Concordaram com a afirmação "é fácil motivar meus alunos" $40 \%$ do grupo E, $32 \%$ do grupo R e $26 \%$ do grupo D. Concordaram com a afirmação "manter a disciplina em sala de aula com os alunos exige muita energia" $75 \%$ do grupo E, $81 \%$ do grupo R e $80 \%$ do grupo D. Concordaram com a afirmação "algumas vezes eu tenho medo dos meus alunos" $11 \%$ do grupo E, $17 \%$ do grupo R e $12 \%$ do grupo D.

Essa relação com os alunos está intrinsecamente ligada à satisfação profissional e ao sentimento de que cumpriu bem seu trabalho, como podemos observar em pesquisas congêneres, tais como a Talis 2013 (ORGANIZATION FOR ECONOMIC CO-OPERATION AND DEVELOPMENT, 2014). Entre os entrevistados na pesquisa TDEBB (OLIVEIRA; VIEIRA, 2010) que concordaram com a afirmação "eu sinto que realizo um trabalho que é socialmente valorizado", registramos 36\% do grupo E, $27 \%$ do grupo R e $21 \%$ do grupo D. Concordaram com a afirmação "os alunos respeitam minha autoridade" $63 \%$ do grupo E, $52 \%$ do grupo R e $49 \%$ do grupo D. Concordaram com a afirmação "no final de um dia de trabalho tenho o sentimento de que os alunos aprenderam alguma coisa" $65 \%$ do grupo E, $53 \%$ do grupo R e $53 \%$ do grupo D. Concordaram com a afirmação "as necessidades dos meus alunos são tão variadas que encontro dificuldades de lhes atender" $35 \%$ do grupo E, $42 \%$ do grupo R e $37 \%$ do grupo D. Concordaram com a afirmação "quando meus alu- 
nos estão indisciplinados, me sinto atordoado(a)" $27 \%$ do grupo E, $37 \%$ do grupo $\mathrm{R}$ e $33 \%$ do grupo D. Concordaram com a afirmação "eu me sinto satisfeito realizando atividades de cuidado com os alunos" $82 \%$ do grupo E, $76 \%$ do grupo R e $72 \%$ do grupo D (Gráfico 1).

Gráfico 1 - Vivência da relação com os alunos

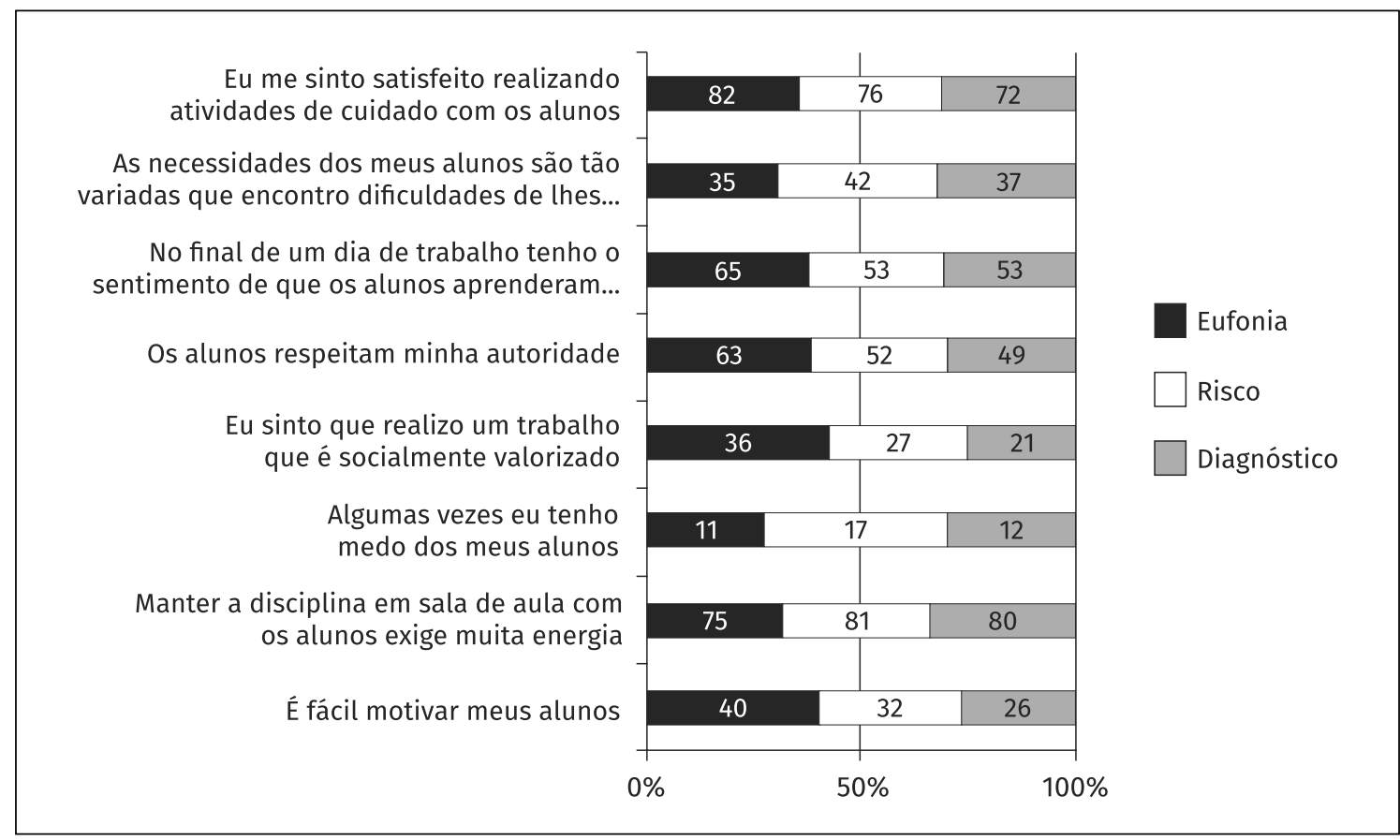

Fonte: Elaborado pelos autores deste artigo a partir dos dados do Survey TDEBB (OLIVEIRA; VIEIRA, 2010).

Merece destaque o fato de que os respondentes dos grupos D e R apresentam uma avaliação mais negativa de sua relação com os alunos. Entretanto, não podemos afirmar se seria consequência de uma vivência negativa do trabalho o desenvolvimento de problema de voz nos professores, ou ainda, se uma saúde vocal prejudicada pode se apresentar como empecilho para o desenvolvimento de boa relação com os alunos.

\section{Medidas de Proteção}

Os dados encontrados na pesquisa TDEBB confirmam os de outras que mostram uma associação entre saúde vocal e o estado de saúde global dos sujeitos e a associação a medidas de proteção tais como a prática de atividades físicas. Observou-se que o número de respondentes que realizam atividades físicas regulares três ou mais vezes por semana é proporcionalmente maior no grupo sem problemas de voz (33\% do grupo E, 26\% do grupo $\mathrm{R}$ e $25 \%$ do grupo D).
Com relação ao consumo de água durante as aulas, outra medida bastante recomendada em muitas campanhas dirigidas aos profissionais que fazem uso constante da voz, observou-se que trata-se de uma prática mais disseminada entre os docentes que já foram diagnosticado com problemas de voz (79\% do grupo D). O grupo de risco e o grupo sem problemas de voz consomem água durante as aulas praticamente na mesma proporção $(67 \%$ do grupo R e $68 \%$ do grupo E), o que sugere que as campanhas de saúde vocal promovidas pelo país ao longo das décadas de 1990 e 2000 atingiram em boa medida seus objetivos de divulgar essa prática preventiva entre os docentes, e que o consumo de água, por si só, não é capaz de promover a saúde vocal dos docentes.

Passamos a utilizar também as informações recolhidas por meio da realização dos grupos focais nas cinco capitais amostradas na pesquisa TDEBB, conforme já explicado. A partir dos relatos dos docentes nos grupos focais, podemos perceber a dimensão integradora da variável saúde para pen- 
sar de forma multidimensional a organização e a gestão do trabalho nas unidades educativas, como o depoimento a seguir:

E: É, são situações assim que precisam também ser revistas, né, num sistema maior. Como é que tá a saúde desse professor, como é que tá sendo os horários dele, aquele espaço que ele tem pra tomar uma água, até mesmo pra sair um pouco da sala, sabe?

Em alguns relatos, a saúde do docente pode ser vista como um indicador-síntese da qualidade da interação professor-aluno, revelando aspectos desgastantes dessa relação para o profissional:

E5: Eu sou muito nova pra enfartar, de você ficar estressado com um aluno e você achar que vai passar mal; ele vai encostar a cabecinha no travesseiro e vai dormir tranquilamente, quem vai ficar passando mal é você, eu acho que sim. Um dos testes que a gente faz pra entrar depois do concurso, exame médico, é o de audição; realmente, depois de trabalhar com os surdos, a minha personalidade até se tornou um pouco surda. É verdade, eu comecei a perceber que qualquer tipo de som mais alto tava me incomodando, mas não era só isso, então às vezes os alunos estão lá fazendo o maior alvoroço e qualquer barulhinho incomoda, então eu acho que deveria existir esse adicional de insalubridade, a nossa saúde é muito debilitada.

Outra dimensão importante no que se refere às condições de trabalho é a carga que o profissional se vê submetido a responder, como se constata no relato de E4: "É igual ele, minha carga horária olha minha voz - a minha carga horária é pesada, eu trabalho de manhã, de tarde e à noite."

De acordo com Silva (2011), a carga de trabalho na literatura específica está dividida em duas dimensões: a física e a psíquica. A dimensão física da carga de trabalho está relacionada aos gestos, às posturas e aos deslocamentos do trabalhador, necessários à execução da tarefa. A quantidade e a qualidade do esforço físico, despendido por cada trabalhador na realização da tarefa, expressa a carga física da jornada de trabalho. Já a carga mental é dividida em cognitiva e psíquica, sendo que a primeira refere-se às exigências mentais na realização do trabalho e pode manifestar-se nas situações em que há necessidade intensa de memorização, atenção, concentração, acuidades visual e auditiva e tomada de decisões. O mesmo autor considera que as diferentes situações de trabalho associadas às características pessoais dos trabalhadores e à rigidez da organização do trabalho podem revelar-se como carga psíquica. A carga psíquica pode ser representada como a resultante da confrontação ente os desejos do trabalhador e da empresa.

A carga pode ainda estar associada à intensificação do trabalho, ou seja, vai se tornando mais pesada à medida que o profissional tem de responder por um número maior de exigências, traduzidas em tarefas e compromissos que lhes são atribuídos. $\mathrm{Na}$ atividade docente, a ampliação do calendário esco$\operatorname{lar}^{2}$ e suas etapas é um indicador dessa intensificação. No exercício docente um aspecto que merece atenção são os ciclos de adoecimento, correlatos ao calendário escolar, o que coloca em evidência a relação do adoecimento com a intensificação do trabalho, como se observa no relato a seguir:

E4: A gente, lá na minha instituição, ela falou assim: 'O primeiro semestre foi tão tranquilo, no segundo semestre a gente tá tendo tanta gente doente, tanto atestado'. Ela falou: 'Cintia, repara, todo ano é assim, no inicio do ano a gente tá bem, quando chega no segundo semestre, de setembro pra frente, todo mundo começa a adoecer'. E não é porque a pessoa quer ir e pegar atestado não, é porque as pessoas estão doentes mesmo.

Esse ciclo de adoecimento é tão coincidente com o calendário escolar (que se desenvolve nos países do hemisfério sul concomitante ao ano civil) que se convencionou chamar esse fenômeno de "outubrite", fazendo uma relação com os problemas de saúde e os constantes afastamentos que aparecem a partir do mês de outubro.

No caso específico da voz, algumas medidas são criadas para mitigar o problema, mas é necessário pensar de forma mais sistêmica soluções que permitam mudar as condições de produção desse processo de adoecimento. Nos depoimentos recolhidos nos grupos focais, essa é uma demanda urgente:

E11: Eu queria só enfatizar ainda as consequências da saúde do professor, né. Eu, durante toda a minha carreira, eu nunca usei aparelho nenhum, aparelho nenhum pra apoio. Hoje eu tenho necessidade de usar

2 A partir da Lei de Diretrizes e Bases da Educação Nacional (Lei 9.394) de 1996, o calendário escolar passou de 180 para 200 dias letivos, que no Ensino Fundamental deve compreender pelo menos 800 horas. 
um microfone que foi distribuído pelo Estado, isso é uma coisa muito boa, foi muito interessante isso, já é o segundo aparelho que eles distribuem, graças a ele o professor ainda tá dando aula com qualidade, né? Se não fosse esse aparelho, eu e a professora, estava fanha porque eu também fico assim se eu não usar o aparelho, eu sinceramente não aguento dar aula.

Algumas discussões realizadas durante os grupos focais pelos docentes evidenciam relações complexas entre intensificação, licença e culpabilidade pelo adoecimento. Nos depoimentos fica evidenciada a percepção dos docentes sobre as dificuldades para ter o reconhecimento institucional de que o profissional está doente e necessita de cuidados:

E6: A maioria trabalha mesmo 42 aulas, e 42 a gente tá falando a nível de Estado, porque na rede privada [...] tem gente, eu não sei como dá conta de trabalhar tanto, a gente vê depois na saúde, o pessoal tá muito adoecido, sabe, tem gente saindo da sala de aula surtado mesmo, de verdade! Tô falando de surto, não é brincadeira não, e no Estado também, quando você tiver andando de cadeira de roda, de muleta, de qualquer trem, cê tem que tá trabalhando, porque não tem licença pra nada não, e também as que a gente tem direito, que é garantia nossa, que é licença prêmio, a gente não consegue tirar de maneira nenhuma, só se cê tiver um amigo que trabalha no seguro, aí eles conversam [...] e aí conseguem, ou quem tá muito doente e tá tirando muita licença aí, consegue também porque tá dando trabalho [...] tá sempre passando pela junta médica [...] pra passar pela junta médica tem que tá muito ruim. Tem uma colega nossa, no ano atrasado, que ela passou pela junta médica, tava andando de cadeira de roda e tudo e o pessoal: 'não, mas tem que voltar pra sala' e tal, e ela ruim pra caramba, foi pra sala de aula e morreu na sala de aula.

\section{Contexto Profissional}

O contexto profissional é tomado aqui como o segundo nível de nossa análise das condições de trabalho para a saúde vocal dos professores. Buscamos identificar variáveis tais como: o vínculo de trabalho com a rede de ensino, o cargo ocupado, a etapa de atuação na educação básica, o tempo de trabalho na função, a carga horária semanal e a jornada de trabalho diária. Consideramos que essas variáveis constituem-se em fatores de risco para a saúde vocal, podendo, portanto, influenciar os padrões de adoecimento.

Com relação ao cargo ocupado, observou-os que os docentes que exercem o cargo de professor são sobrerrepresentados no grupo R, confirmando a literatura que indica que a profissão docente, tradicionalmente incluída na categoria de "profissões da voz", é de risco para os problemas de voz (ROY, 2004). Os profissionais que exercem a função de professor são $41,6 \%$ do grupo E, $75 \%$ no grupo D e 55,5\% do grupo R, enquanto nos não professores a tendência se inverte: $53,5 \%$ se enquadram no grupo E e 44,2\% no grupo R. Ou seja, dentre todos os trabalhadores docentes da amostra, aqueles que assumem a função de professor em sala de aula são os que apresentam maior risco para problemas de voz, embora este risco também esteja presente nas outras funções (supervisores, bibliotecários etc.).

Com relação ao vínculo empregatício, observa-se que profissionais concursados relatam mais problemas de voz e são mais diagnosticados com problemas de voz (64\% do grupo E; $70 \%$ do grupo $\mathrm{R} ; 80 \%$ do grupo $\mathrm{D})$, enquanto profissionais contratados temporariamente relatam menos problemas de voz (36\% do grupo E; $29 \%$ do grupo R; $20 \%$ do grupo D). Uma interpretação possível é que o vínculo estável propicia a busca de auxílio médico sem riscos ao seu emprego, enquanto os profissionais contratados, que possuem vínculo instável, podem estar mais suscetíveis a serem sub stituídos ao apresentarem problemas de saúde que podem afetar seu desempenho profissional. Esses profissionais possivelmente têm menor acesso a programas de saúde do trabalhador e a planos de saúde, além de serem geralmente mais jovens e por isso terem maior capacidade para suportar as cargas de esforço vocal, contudo essas são possibilidades a serem exploradas em estudos futuros.

A etapa de atuação na educação básica também é uma variável que se associa com a distribuição dos problemas de voz. Embora no ensino médio se observe uma distribuição uniforme de sujeitos com e sem problemas de voz, constata-se que o grupo R e o grupo D são sobrerrepresentados no ensino fundamental. O grupo E de nossa amostra compõem-se de $55 \%$ de profissionais que atuam no ensino fundamental, enquanto o grupo R está composto 
de $60 \%$ de profissionais que atuam nesta etapa e o grupo D, 68\%. Na educação infantil observa-se a tendência oposta. Estes profissionais representam $27 \%$ do grupo E, $22 \%$ do grupo R e $15 \%$ do grupo D. Os dados nos sugerem que o ensino fundamental seria a etapa da educação básica de maior risco para os problemas de voz, e a educação infantil a etapa de menor risco.

Com relação ao tempo de trabalho em educação, os profissionais que trabalham de 15 a 30 anos representam quase a mesma proporção dos grupos E e R: $37 \%$ e $36 \%$, respectivamente. Entretanto, os profissionais mais experientes constituem 52\% dos profissionais do grupo D. Os profissionais mais jovens, que atuam a menos de 15 anos em educação, são $59 \%$ do grupo E, $60 \%$ do grupo R e $44 \%$ do grupo D. Este dado nos leva a pensar que o tempo de exposição aos fatores de risco e a idade não estão tão claramente associados às variáveis de risco para os problemas vocais, mas que o fato de estarem há mais tempo na rede cria a possibilidade de pedirem e obterem licença médica, o que se encontra associado à mudança no seu perfil em relação ao vínculo de trabalho.

Algumas hipóteses presentes na literatura indicam que a jornada de trabalho é um importante fator de risco (ARAÚJO et al, 2008), o que nossa pesquisa confirma ao identificar maior prevalência de problemas de voz entre profissionais da educação que exercem mais de um cargo. Observamos que os professores sem problemas (Grupo E) concentram-se no grupo que atua em apenas uma escola (58\%). No grupo R, apenas $50 \%$ trabalham em um só estabelecimento, e entre os professores do grupo D, 44\% trabalham em apenas uma unidade educativa. Entre os professores que trabalham em duas escolas acontece a tendência inversa: eles são $34 \%$ do grupo E, 39\% do grupo R e 47\% do grupo D.

Em questão específica sobre a carga horária observamos que os profissionais que afirmaram exercer maior tempo semanal de docência também declaram mais problemas de voz. Os professores que declaram atuar de 30 a 40 horas semanais em atividade docente são $19 \%$ do grupo E, $23 \%$ do grupo R e $25 \%$ do grupo D. Por outro lado, os professores que trabalham até 25 horas semanais são $65 \%$ do grupo E, $62 \%$ do grupo R e $65 \%$ do grupo $\mathrm{D}$, o que sugere que o número de horas de trabalho semanal correlaciona-se positivamente com o aparecimento de sintomas vocais.

Sintetizando, podemos dizer, com base nos dados recolhidos, que o perfil do trabalhador de risco para problemas de voz associa-se a professoras mulheres que trabalham no ensino fundamental, em mais de uma jornada, com vínculo empregatício estável. Os professores diagnosticados com problemas de voz têm basicamente o mesmo perfil, mas são mais velhos e habitam as capitais.

\section{Contexto Ambiental}

Em um terceiro nível de análise, o contexto ambiental do trabalho docente é analisado considerando-se as condições físicas das escolas, de um modo geral. Tomamos aqui as variáveis nível de ruído percebido, ventilação, iluminação, condições das paredes, condições da sala de convivência e repouso, condições dos banheiros, equipamentos, tamanho do município, buscando averiguar em que medida se constituem em condições que afetam a saúde vocal dos professores.

Além dessas variáveis mais relacionadas à unidade educativa, o tamanho do município é tomado aqui como uma variável que se relaciona a fatores de riscos ambientais e precarização das condições do trabalho. Observou-se que o grupo E é um pouco maior em municípios com menos de 50 mil habitantes (46,2\%, sendo $44,6 \%$ em capitais), que o grupo R se equivale e que o grupo D é bem maior nas capitais $(2,0 \% \mathrm{em}$ municípios com menos de 50 mil habitantes e 3,3\% em capitais), sugerindo que, ainda que as condições que levem ao aparecimento dos sintomas não sejam tão diferentes entre cidades de maior ou menor porte, a relativa facilidade de acesso ao sistema de saúde encontrado nas capitais pode estar relacionada com um aumento do número de diagnósticos.

\section{Condições físicas das escolas}

Em nosso estudo observamos que os grupos $\mathrm{R}$ e $\mathrm{D}$ tendem a relatar com mais frequência que o grupo E que são expostos a níveis de ruído elevado ou insuportável: a) originados na sala de aula; b) fora dela; ou c) fora da unidade educacional. $\mathrm{O}$ grupo E avalia o ruído como insuportável: a) 32\% dos casos; b) $32 \%$ dos casos; e c) $20 \%$ dos casos. $\mathrm{O}$ 
grupo R relata ruído elevado ou insuportável mais frequentemente: a) 44\% dos casos; b) $40 \%$ dos casos; e c) $25 \%$ dos casos. Já o grupo D relata estar exposto a ruído elevado ou insuportável em: a) 48\% dos casos; b) $41 \%$ dos casos; e c) $26 \%$ dos casos.

A percepção do ruído está fortemente associada com o tamanho do município. Quando desagregamos os dados apresentados acima, observamos grande diferença entre capitais e municípios com menos de 50 mil habitantes: nos primeiros, avalia-se o ruído em sala de aula como insuportável em $10,4 \%$ dos casos, e nos segundos, em apenas 5,2\% dos casos. Os achados se repetem para os ruídos dentro da unidade educacional e fora da sala de aula: $10 \%$ em capitais e $4,2 \%$ em municípios menores; e o ruído gerado fora da unidade educacional é considerado insuportável nas capitais em 7,9\% dos casos e em 3,9\% dos casos em municípios menores.

Observa-se que os grupos com problemas de voz também avaliaram de forma mais negativa outras variáveis relacionadas às condições ambientais da unidade educativa, como a ventilação, a iluminação, as condições das paredes, as condições da sala de convivência e repouso e as condições dos banheiros dos funcionários (Gráfico 2). Este dado sugere uma associação entre o perfil de risco para problemas de voz e uma percepção mais crítica das condições físicas da escola. Existe também uma associação entre o tamanho dos municípios e a percepção das condições ambientais, sendo todas as variáveis acima mencionadas, exceto a condição das paredes, avaliadas de forma significativamente pior nas capitais que em municípios de até $50 \mathrm{mil}$ habitantes. Contudo, não se pode aqui afirmar que as condições ambientais precárias são causa do perfil de risco e dos diagnósticos, ou se este perfil de saúde induz a uma leitura mais crítica do ambiente físico do trabalho. Também não se pode afirmar que as condições ambientais sejam significativamente piores na capitais ou se os professores das capitais são mais críticos em relação a elas. Provavelmente ambas as influências ocorram nos dois casos.

Gráfico 2 - Condições ambientais da unidade educativa avaliadas negativamente

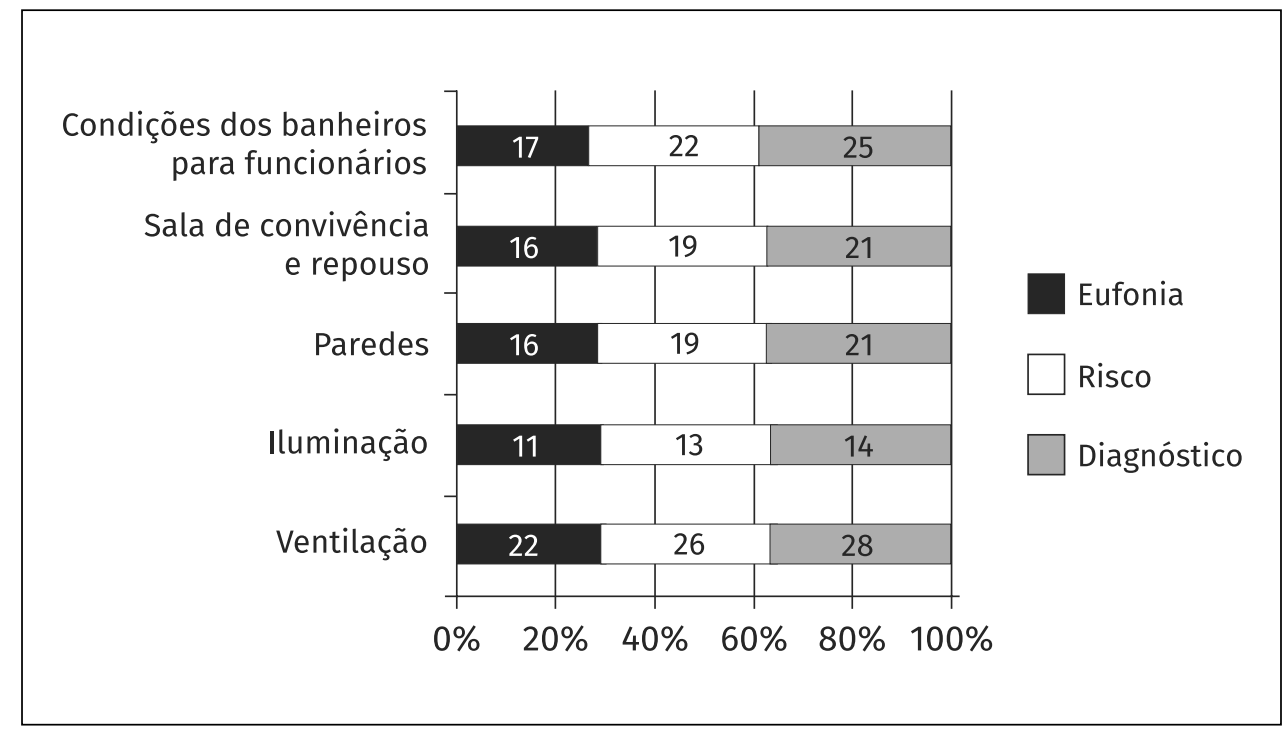

Fonte: Elaborado pelos autores deste artigo a partir dos dados do Survey TDEBB (OLIVEIRA; VIEIRA, 2010).

Outras variáveis relacionadas às condições de trabalho voltadas para os alunos, tais como condições dos equipamentos (TV, vídeo, som), condições da sala de informática, condições dos recursos pedagógicos, condições da biblioteca, condições dos parquinhos, áreas de recreação e da quadra de esportes foram pior avaliadas pelo grupo $\mathrm{R}$, mas não pelo grupo D. Estas variáveis também foram 
pior avaliadas pelos professores das capitais que por professores de municípios menores, exceto a condição da biblioteca, que os professores de cidades menores avaliaram com maior frequência como insuportável.

Considerando os fatores de risco ambiental para os problemas de voz, os dados indicam que de modo geral professores com perfil de risco para problemas de voz relatam ambientes de trabalho mais ruidosos e em piores condições que os professores do perfil sem problemas de voz.

\section{Contexto Global}

O quarto nível de análise das condições favoráveis e obstáculos para a saúde vocal dos professores aborda o que foi denominado contexto global, voltando-se para a análise de condições que levariam a uma intensificação do trabalho docente, como a presença ou não de apoio, número de alunos em média por sala de aula e presença de trabalho coletivo na escola.

A intensificação do trabalho, seja pelo aumen- to da cadência ou do número de horas dedicadas ao trabalho, revela-se um fator de risco para problemas de voz, pois em um ritmo acelerado, as pausas para a recuperação do tecido laríngeo, desgastado pela excessiva fonação, tendem a ser menores. O número de alunos por sala é uma variável muito associada à intensificação do trabalho docente, e em nosso estudo correlacionou-se positivamente com os problemas de voz. Considerando professores que atuam em salas de até 25 alunos, eles são $40 \%$ dos professores do grupo E, $35 \%$ dos professores do grupo R e $26 \%$ dos professores do grupo D. Por outro lado, considerando professores com turmas de 25 a 45 alunos, eles são 43,5\% do grupo E, 53,5\% do grupo R e $59 \%$ do grupo D (Gráfico 3). Apresentando a correlação entre número da alunos e perfil de problemas vocais de outra forma, a média do número de alunos do grupo E é de 26,7 alunos, do grupo R é de 28,6 e do grupo D é de 28,8 . Vemos, portanto, que a variável número de alunos por turma correlaciona-se positivamente com o risco de problemas de voz.

Gráfico 3 - Número da alunos por turma e perfil de problemas vocais

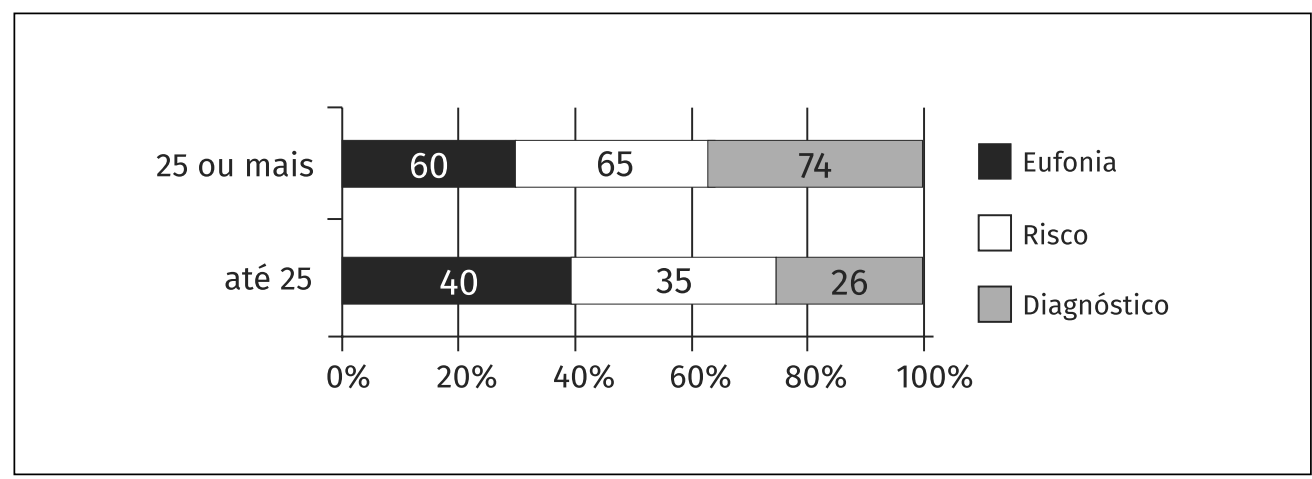

Fonte: Elaborado pelas autoras deste artigo a partir dos dados do Survey TDEBB (OLIVEIRA; VIEIRA, 2010).

Outra variável analisada, associada à intensificação do trabalho, foi a presença de pessoal de apoio. O grupo $\mathrm{R}$ relata menor apoio de pessoal para acompanhamento de seus alunos que o grupo sem problemas de voz. Enquanto $42 \%$ dos profissionais do grupo $\mathrm{R}$ relata não ter apoio, apenas $36 \%$ relata o mesmo nos grupos E e D. Estes dados, que indicam uma correlação positiva entre presença de apoio para a realização do trabalho e saúde vocal, são reforçados quando analisamos os dados sobre a realização de atividades coletivas. Observou-se que o grupo sem problemas de voz realiza mais atividades com seus colegas que o grupo com problemas de voz. Infere-se que o trabalho coletivo pode ser um importante fator de proteção para os problemas 
de voz. Conforme pode-se observar no Gráfico 4 , a realização de atividades coletivas na escola revela-se amplamente associada a uma maior saúde vocal.

Gráfico 4 - Trabalho coletivo e perfil de problemas vocais

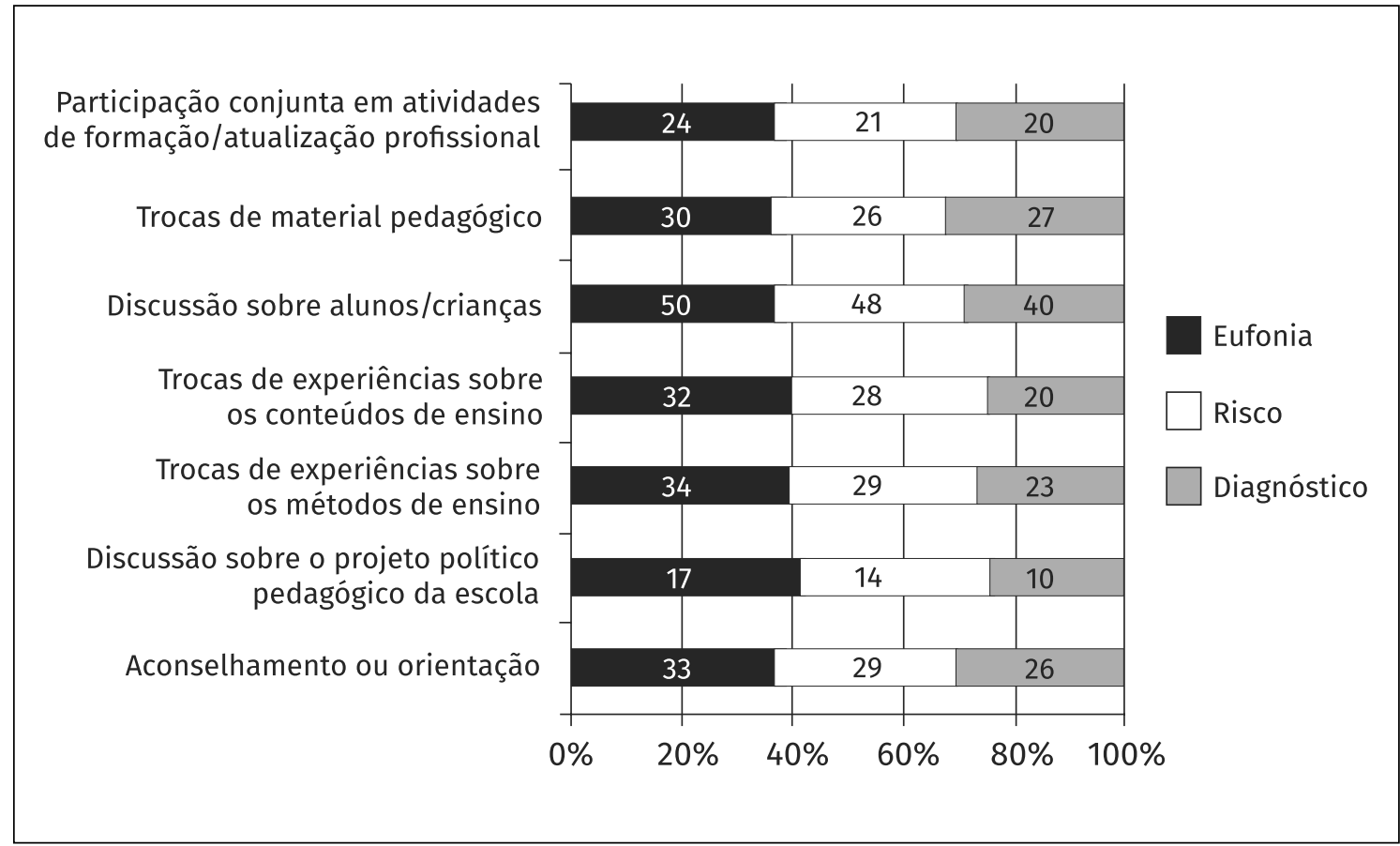

Fonte: Elaborado pelas autoras deste artigo a partir dos dados do Survey TDEBB (OLIVEIRA; VIEIRA, 2010).

Esse dado vai ao encontro dos achados de Doudin, Curchod-Ruedi e Moreau (2011), que analisam a importância do suporte social como fator de proteção ao desgaste do professor. A correlação entre a realização de atividades coletivas e maior saúde vocal sugere a relevância da participação coletiva dos docentes na organização do trabalho pedagógico na escola como importante medida de proteção. Por outro lado, observa-se que o perfil de risco para o adoecimento vocal está associado ao aumento do número de alunos nas turmas, ausência de apoio de colegas para a realização do trabalho docente e pouca frequência da realização de atividades coletivas na unidade educativa.

Os grupos com problema de voz relatam, de modo geral, maior aumento na carga de trabalho quando questionados sobre mudanças no seu trabalho nos últimos anos (Gráfico 5). Os grupo R e D relatam ampliação da jornada em $35 \%$ e $36 \%$ dos casos, respectivamente, enquanto no grupo E se verifica incidência menor de relatos de ampliação da jornada, o que ocorreria em 30\% dos casos. Outras questões analisadas apontam para um aumento não apenas da demanda, ou seja, da carga de trabalho, que leva à intensificação dos ritmos, mas também para um aumento do controle. As questões que tangenciam o tema do controle são menos conclusivas no que diz respeito à sua correlação com os três grupos analisados, mas sugerem que o aumento da demanda, simultâneo ao aumento do controle, não aumentaria os riscos para a saúde vocal. Por exemplo, relatam ter observado recentemente uma maior supervisão/controle de suas atividades: 56\% do grupo E, $58 \%$ do grupo R e $50 \%$ do grupo D; perda de autonomia na definição de suas atividades: $16 \%$ do grupo E, $17 \%$ do grupo R e $19 \%$ do grupo $\mathrm{D}$; incorporação de novas funções e responsabilidades: $67 \%$ do grupo E, $68 \%$ do grupo R e $72 \%$ do grupo D. 
Gráfico 5 - Carga de trabalho e perfil de problemas vocais

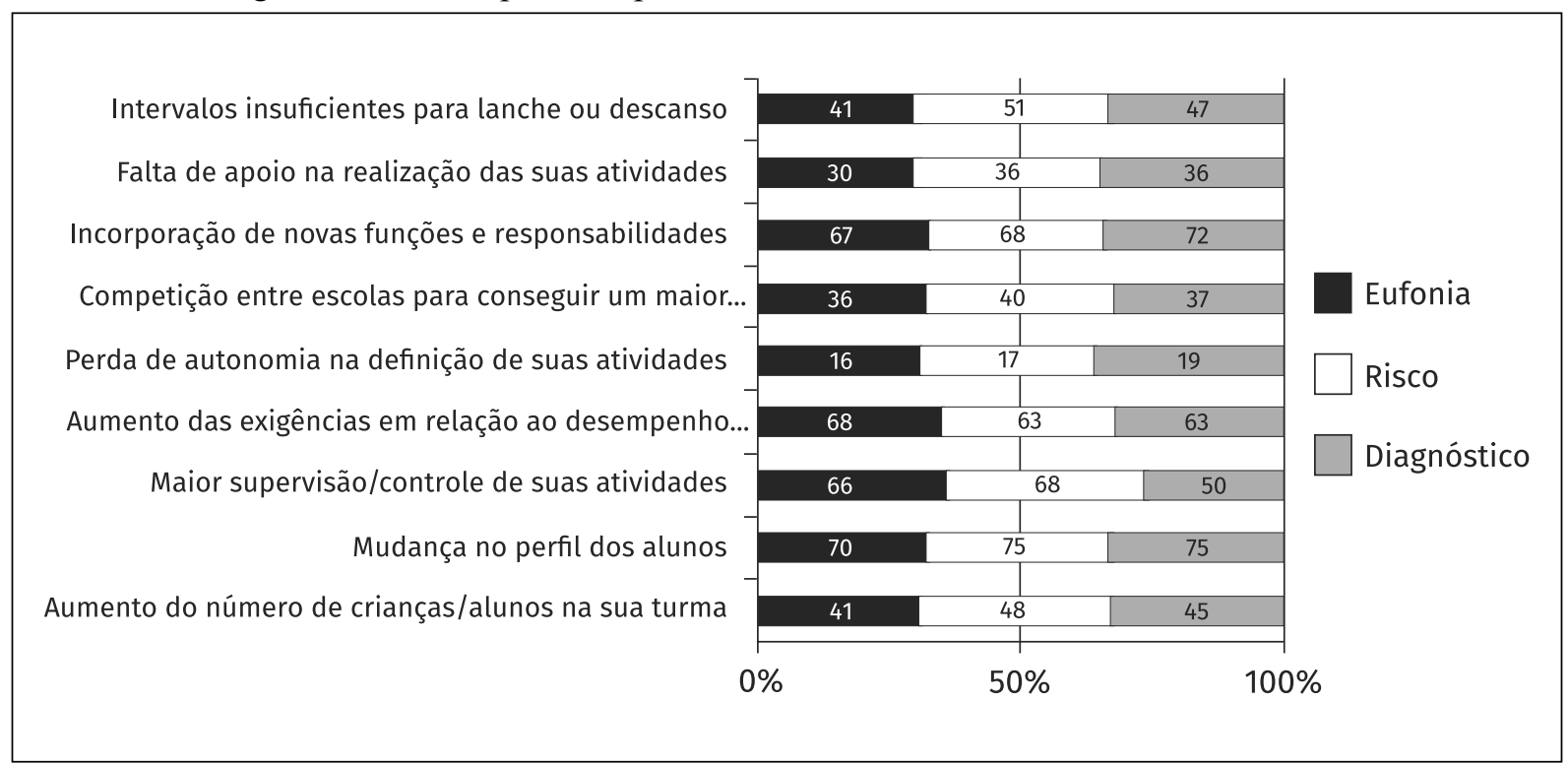

Fonte: Elaborado pelas autoras deste artigo a partir dos dados do Survey TDEBB (OLIVEIRA; VIEIRA, 2010).

Em síntese, o contexto global remete aos ritmos do trabalho e questões de fundo relacionadas à organização do trabalho. Como já foi observado, a extensa jornada e o número médio de alunos por turma são importantes fatores de risco para os problemas de voz relacionados ao trabalho. Observa-se ainda que estratégias de redução do número de alunos por turma e dedicação exclusiva a uma única unidade educacional como medidas para a melhoria do seu trabalho na percepção dos docentes, são ainda mais assinaladas por aqueles com problemas de voz (grupos D e R) que por docentes eufônicos. ${ }^{3}$

\section{Considerações finais}

A grande defasagem entre os docentes que relatam sintomas vocais e o número de licenças motivadas pela agudização do problema nos sugere um caráter crônico destes sintomas nas unidades de educação básica pesquisadas. Trata-se, portanto, de um sintoma bastante presente na docência, com o qual a grande parte dos profissionais se adapta e passa a conviver em seu cotidiano.

3 Os docentes responderam da seguinte forma: reduzir o número de alunos/crianças por turma: $53 \%$ grupo $\mathrm{E}, 61 \%$ grupo $\mathrm{R}$ e $62 \%$ grupo $\mathrm{D}$; ter dedicação exclusiva a uma única unidade educacional: $32 \%$ grupo E, $34 \%$ grupo R e $41 \%$ grupo D.
Os dados da pesquisa mostraram que os desafios para promover a saúde vocal dos professores são muitos e ultrapassam a abordagem higienista que vinha sendo a tônica em décadas passadas. Mais que promover campanhas para o bom uso da voz e mudanças de comportamento que tendem a gerar culpa no docente que adoece apesar das orientações, importa cada vez mais pensar em medidas articuladas que propiciem um ambiente de trabalho saudável e uma organização do trabalho que considere as necessidades humanas dos trabalhadores, que seja compatível com a saúde deles, a partir de uma análise em vários níveis, como a que nos propusemos a fazer aqui.

Os dados da pesquisa TDEBB confirmaram correlações já estabelecidas na literatura entre variáveis ambientais como nível de ruído e o adoecimento vocal. Observou-se também o efeito sobre a saúde vocal de variáveis organizacionais como classes numerosas e elevada jornada de trabalho semanal, confirmando relatos encontrados na literatura nacional e internacional. A consideração de tais evidências poderia contribuir para criar regulamentações nesta direção. No momento em que o país discute as condições de trabalho e carreira dos profissionais da educação básica, como uma exigência do Plano Nacional de Educação, Lei 
13.005/2014 (BRASIL, 2014), é oportuno atentar para os riscos que a atual organização do trabalho escolar tem acarretado para esses profissionais. Desde já, consideramos que a promoção de boas condições de trabalho revela-se estratégia central visando à promoção da saúde vocal dos docentes. Como medidas mais urgentes, a redução do número de alunos por turma e a atenção a fatores ambientais de risco para a saúde vocal, com destaque para os níveis de ruído ambiental, aparecem como importantes sugestões apresentadas pelos próprios docentes.

Os dados da pesquisa mostram que os docentes com perfil de adoecimento vocal têm uma pior percepção de sua profissão e de sua relação com os alunos quando comparados àqueles saudáveis. Na mesma direção, esses professores com problemas de voz revelam menores expectativas com relação ao seu futuro profissional e um maior desejo de abandono da profissão. Os vários aspectos afetivos e psicossociais associados ao perfil de adoecimento vocal analisados sugerem que a saúde vocal deve ser encarada como parte de um problema de implicações mais profundas na relação de ensino-aprendizagem, e não apenas um problema de saúde do trabalho que diz respeito ao trabalhador. Nesse sentido, os esforços para a promoção de uma maior saúde vocal dos docentes valem não apenas como medida para garantir a adequação às leis trabalhistas, zelando por um ambiente de trabalho salubre, mas como meio de promover um ambiente educacional em que as relações pedagógicas sejam vivenciadas de forma mais harmoniosa.

A pesquisa mostrou ainda alguns caminhos possíveis e inovadores que podem ser promissores na promoção da saúde vocal nas unidades educacionais e, por consequência, para a melhoria da qualidade da educação no Brasil. Dentre eles, destacamos a promoção de atividades coletivas como medida de proteção à saúde vocal dos docentes. Nesta direção acreditamos que a promoção da saúde vocal entre os professores deve passar pela discussão da organização do trabalho pedagógico, visando criar estratégias que estimulem trocas de experiência entre os docentes e discussão sobre sua relação com os alunos, em suma, a promoção do trabalho coletivo. Como forma de viabilizar uma organização neste sentido, consideramos que a dedicação exclusiva a uma escola e condições de trabalho mais adequadas às necessidades de pausa para descanso, um ambiente seguro e confortável de trabalho, entre outros aspectos, são importantes estratégias a se considerar.

\section{REFERÊNCIAS}

ARAÚJO, T. M. et al. Fatores associados a alterações vocais em professoras. Caderno de Saúde Pública, Rio de Janeiro, v. 24, n. 6, p. 1229-1238, 2008.

ASSUNÇÃO, A. A.; OLIVEIRA, D. A. Intensificação do trabalho e saúde dos professores. Educação e Sociedade, Campinas, SP, v. 30, n. 107, p. 349-372, maio/ago. 2009. Disponível em: <http://www.cedes.unicamp.br>. Acesso em: fev. 2009.

BEHLAU, M. Voz: o livro do especialista. São Paulo: Revinter, 2001.

BRASIL. Presidência da República. Lei $n^{\circ} 13.005$, de 25 de junho de 2014. Aprova o Plano Nacional de Educação - PNE e dá outras providências. Disponível em: <http://www.planalto.gov.br/ccivil_03/_ato2011-2014/2014/ lei/113005.htm>. Acesso em: 10 maio 2016.

DOUDIN, P. A.; CURCHOD-RUEDI, D.; MOREAU, J. Le soutien social comme facteur de protection de l'épuisement des enseignants. In: DOUDIN, P. A. et al. La santé psychosociale des enseignants et des enseignantes. Québec: Presses de l'Université de Québec, 2011. p. 11-38.

MEDEIROS, A. M.; BARRETO, S. M.; ASSUNÇÃO, A. A. Voice disorder (dysphonia) in public school female teachers working in Belo Horizonte: prevalence and associated factors. Journal of Voice, v. 22, n. 6, p. 676-687, 2008.

MURTA, C. Magistério e sofrimento psíquico: contribuição para uma leitura psicanalítica da escola. In: COLOQUIO DO LEPSI IP/FE-USP, 3., 2001, São Paulo. 
ORGANIZATION FOR ECONOMIC CO-OPERATION AND DEVELOPMENT - OECD. Le rôle crucial des enseignants: attirer, former et retenir des enseignants de qualité. Aperçu. Paris: OECD, 2005.

A Teachers' Guide to TALIS 2013: teaching and Learning International Survey. Paris: OECD, 2014. Disponível em: <http://www.oecd.org/edu/school/TALIS-Teachers-Guide.pdf>. Acesso em: 09 maio 2016.

OLIVEIRA, D. A.; VIEIRA, L. M. F. Trabalho docente na educação básica no Brasil. Base de Dados TDEBB/ GESTRADO. Faculdade de Educação/UFMG. Belo Horizonte, 2010.

ROY, N. et al. Prevalence of voice disorders in teachers and the general population. Journal Speech Language Hearing Research, v. 47, p. 281-293, 2004.

SILVA, N. R. da. Fatores determinantes da carga de trabalho em uma unidade básica de saúde. Ciência \& Saúde Coletiva, Rio de Janeiro, v. 16, n. 8, p. 3393-3402, ago. 2011.

Recebido em: 06.03.2016

Aprovado em: 19.07.2016 